\title{
A Comparison of Low-Level Trajectories in an Urban Atmosphere ${ }^{1}$
}

\author{
LEONARD M. DRUYAN \\ New York University
}

(Manuscript received 12 January 1968, in revised form 3 April 1968)

\begin{abstract}
Throughout the month of June 1965 tetroons ballasted for 150-300 m altitude were released and radartracked in New York City and environs. The study evaluates the skill with which data from both a dense mesoscale network of surface wind observations and a less dense network of balloon-derived wind observations in the planetary boundary layer can be used to reconstruct the tetroon trajectories.

Root-mean-square errors in predicting 2- and 4-hr tetroon positions from surface-wind-derived trajectories are reduced by the addition of a vector correction to account for vertical wind shear; this correction also randomizes the direction of the errors. Corrected surface wind trajectories, when compared with the tetroon trajectories, are slightly better than those computed from the balloon-derived winds.

The best results obtained yield rms 2-hr prediction errors of $15 \mathrm{~km}$; the median error of this distribution expressed as a percentage of the range of each tetroon flight was $36 \%$.
\end{abstract}

\section{Introduction}

Constant volume balloons (tetroons) have been found useful in providing accurate air trajectory information in the boundary layer over urban areas (Angell et al., 1966), as well as at higher altitudes (Angell, 1961). However, a dynamic approach to the prediction of air pollution concentrations requires air trajectory information continuously over time and space. The desired data density can only be obtained at present by switching over from the Lagrangian to an Eulerian system.

This study evaluates the use of surface and planetary boundary layer wind observations, hereafter referred to as upper winds, for estimating low-level trajectories by comparing them to the actual trajectories of tetroons which were released in and around New York City in June 1965. A general analysis of the behavior of the tetroons as observed in this study has been reported by Hass et al. (1967). The experiment was part of a larger study already described by Davidson (1967) and was carried out as a cooperative venture between the Air Resources Laboratory of the Environmental Science Services Administration and New York University.

\section{Discussion of data}

The tetroons were tracked by WSR-57 weather radar mounted atop the RCA building in midtown Manhattan. Although this radar positioned the tetroon adequately in the horizontal, its ability to measure elevation angles and thus tetroon altitudes, proved unreli-

\footnotetext{
${ }^{1}$ Contribution No. 70, Geophysical Sciences Laboratory, Department of Meteorology and Oceanography, New York University. Revised from an M.S. thesis supported by the National Center for Air Pollution Research of the U. S. Public Health service under Grant No. AP-00328-04.
}

able. However, helicopter tracking (conducted by Sign$\mathrm{X}$ Laboratories, Inc.) for 16 flights verified mean flight altitudes varying roughly between 150 and $600 \mathrm{~m}$. The altitude profiles revealed considerable vertical oscillation of the in-flight tetroons with an amplitude often as large as $50 \%$ of the mean amplitude.

Although a total of 55 tetroons were released during the experiment, only 31 were found suitable for this study. Those flights which showed a sharp directional change (due to the sea breeze front) within the first $2 \mathrm{hr}$ after launching were eliminated as were flights which could not be tracked longer than $2 \mathrm{hr}$.

Surface wind data were collected from Weather Bureau, Coast Guard, Navy, Air Force and Flight Service Station Observatories, all operating at the various airports and Coast Guard stations in the metropolitan area and the Weather Bureau Central Park station. Additional data were collected from other institutions which maintain wind sensing equipment for their own use. This latter group includes schools, museums, public health authorities and industrial plants. Total data coverage at any one time ranged from 30-60 simultaneous observations over the area.

The data from these sources were either in the form of continuous recordings of wind speed and direction or instantaneous observations taken within $15 \mathrm{~min}$ of each hour. (Weather Bureau regulations provide for a 3-min average for official airways observations.)

Since a majority of the surface wind sensing instruments were owned and maintained by agencies independent of the research teams conducting the tetroon experiment, it was impossible to be sure of the accuracy of their data in every case. Some subjectivity was therefore allowed in rejecting those infrequent observations 


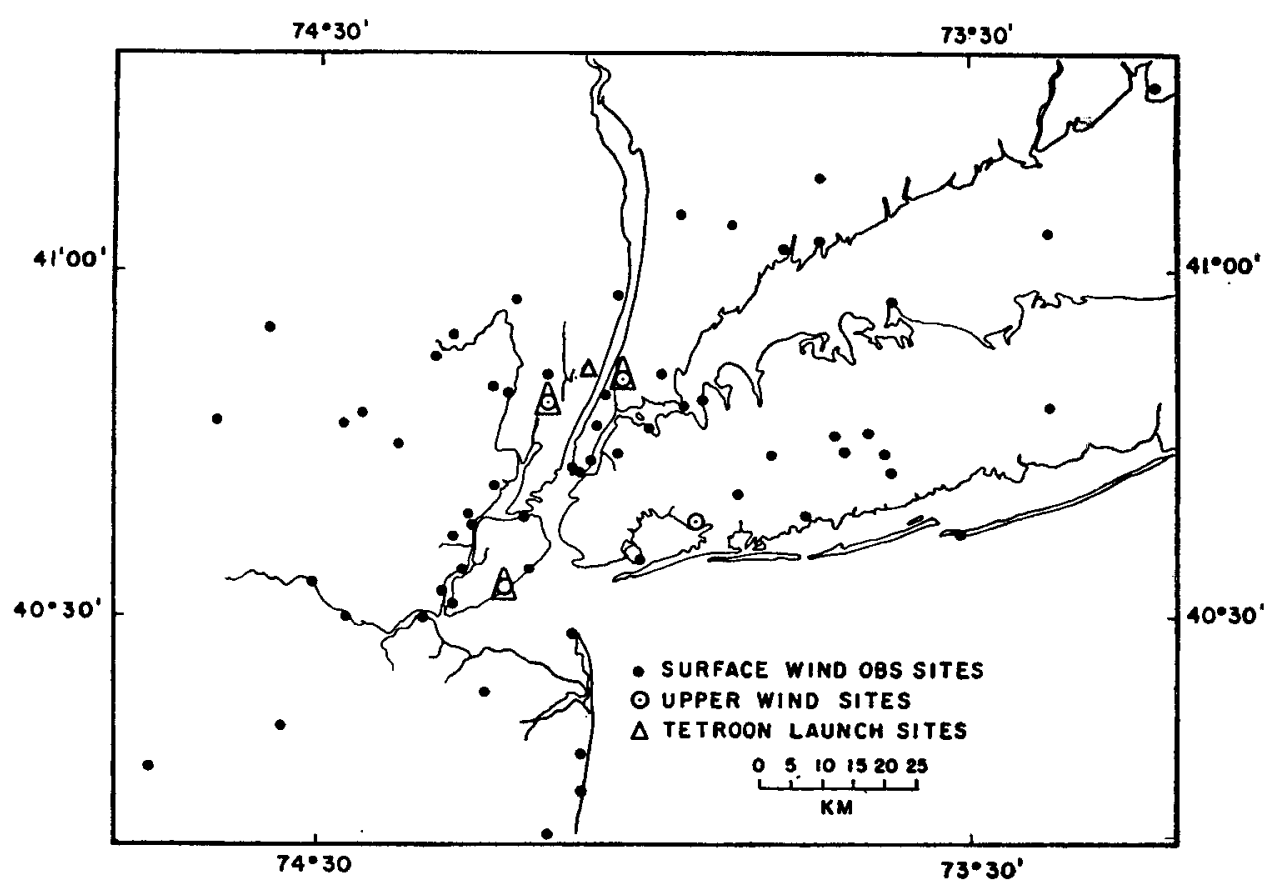

FIG. 1. New York City urban area and locations of tetroon launch sites, surface wind recording sites and sites of upper wind observations.

which were inconsistent with nearby simultaneous observations.

Upper wind data were available from three pibal sites where observations were taken by the New York University research team, and from Kennedy International Airport where the 6 -hr radiosonde observations are taken by the U.S. Weather Bureau. The pibal data were derived from single theodolite, manual observations of 45 -gm lift balloons. Readings were taken at 15 -sec intervals and balloons were launched usually every hour during the tetroon experiment. The Kennedy Airport data consisted of elevation and azimuth readings of balloon position taken at 6 -sec intervals. Although this detail is not routinely available for radiosonde observations, it was supplied by the Weather Bureau upon request.

Fig. 1 shows the urban area under study and the locations of tetroon launch sites, surface wind recording sites and sites of upper wind observations.

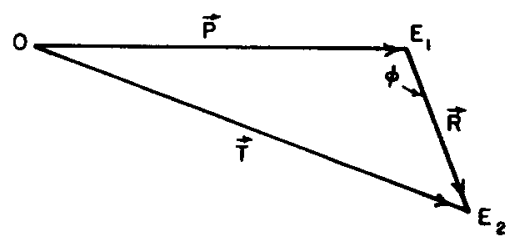

FiG. 2. Comparison of surface wind trajectories with tetroon trajectories. $\mathrm{O}$, launch site; $\mathrm{E}_{1}$, end point of wind derived trajectory; $E_{2}$, end point of tetroon trajectory; $\mathbf{P}$, position vector of wind derived trajectory; $\mathbf{T}$, position vector of tetroon trajectory; $\mathbf{R}$, vector error of magnitude $R$ and direction $\varphi$.

\section{Tetroon trajectories vs surface wind trajectories}

a. Construction of surface wind trajectories. The continuous recordings of surface wind were averaged hourly from one-half hour before to one-half hour after each designated map time. These observations, along with the instantaneous readings of surface wind speed and direction, were plotted on maps of the New York urban area. The wind fields thus portrayed were analyzed with conventional streamflow lines and isotachs.

Each wind-derived trajectory was begun at the tetroon launch site and continued along the streamflow line passing through that point on the map whose designated time was closest to the launching. The length of the trajectory segment was made proportional to the average value of the isotachs over the segment. Since each map was considered valid for the hour centered about its designated time, the trajectory thus drawn was continued on a given map for that hour or whatever fraction of it which was desired. Two-hour duration trajectories were derived for each flight from the surface wind fields and were continued to 4-hr lengths where possible.

$b$. Comparison of surface wind and tetroon trajectories. The 31 tetroon flights were divided into a test group of 16 and a control group of the remaining 15 . The comparisons, made for the test group data, are best illustrated by Fig. 2. The vector $\mathbf{R}$, computed for each comparison, and hereafter referred to as the vector error, has a magnitude equal to the distance between the wind and tetroon trajectory end points, and a 


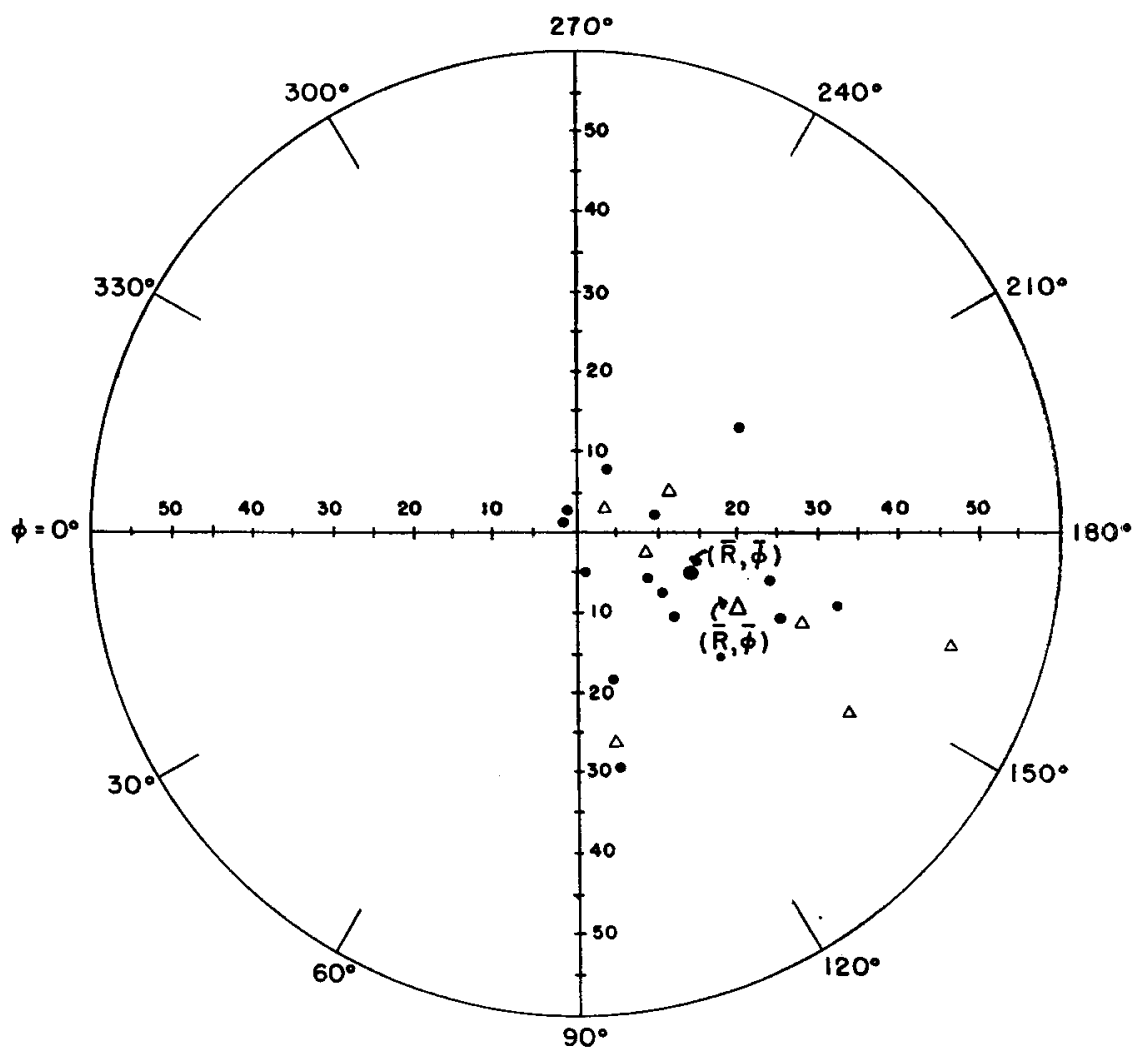

FIG. 3. Distribution of vector errors for 2-hr (solid circles) and 4-hr (triangles) test group comparisons of surface wind vs tetroon trajectories. $\mathrm{MVE}_{2}=15 \mathrm{~km}, 157^{\circ} ; \mathrm{MVE}_{4}=22 \mathrm{~km}, 155^{\circ}$.

direction determined by the angle $\varphi$ which is measured as positive counterclockwise from the position vector of the wind-derived trajectory $\mathbf{P}$. For those cases where $90^{\circ}<\varphi<270^{\circ}$, the tetroon position, at the time of comparison, was further downwind than the corresponding surface wind trajectory position. Moreover, since the comparisons reflect the wind fields at two different altitudes, cases where $0^{\circ}<\varphi<180^{\circ}$ indicate a veering of wind with height and $180^{\circ}<\varphi<360^{\circ}$ indicates backing of the wind with height.

Each vector error was resolved into its orthogonal components in the $\varphi=0^{\circ}$ and $\varphi=90^{\circ}$ directions. A mean vector error (MVE) was computed from the means of these components for each of the 2- and 4-hr duration comparison groups.

Fig. 3 shows the distribution of vector errors for test group flights for 2- and 4-hr durations. The origin is at $E_{1}$ of Fig. 2 (the end point of the surface-windderived trajectories of these durations). The angular coordinate $\varphi$ is the same as in Fig. 2. The radial coordinate represents the magnitude of the vector error in $\mathrm{km}$; the mean vector errors are indicated.

It can be seen that the 2- and 4-hr surface wind trajectories were generally shorter (in length) than the simultaneous tetroon trajectories of the respective time durations. Most of the vector errors reflect the directional veering of wind with height in the planetary boundary layer, as well as the positive wind speed shear (i.e., in most cases $90^{\circ}<\varphi<180^{\circ}$ ).

c. Derivation of predictors. An attempt was' made to modify the surface wind trajectory so that it could be used to better determine actual tetroon positions. The mean vector errors of the test group 2- and 4-hr comparisons were considered representative of the systematic errors and were consequently used as predictors; a predicted position is uniquely determined by the vector addition of the mean vector error and the position vector of the wind-derived trajectory. Application of the predictors on the control group trajectories is discussed in Section 5.

Alternative predictors were derived by assuming a linear relationship between tetroon downwind range and surface wind trajectory range and evaluating the dependency by the method of least squares. (The different stability regimes of nighttime and early morning vs daytime were considered by two separate regression equations.) One prediction scheme used a constant angular correction to account for veering, while the second assumed a dependence of the directional error on downwind range. Although the predictions made according to these schemes reduced some of the original errors in tetroon positioning, they did not prove as effective on independent data as those made using the MVE predictors. 


\section{Tetroon trajectories vs upper wind trajectories}

In order to interpolate between observations of upper wind and to obtain a representative field, a smooth isogon-isotach analysis of the upper winds was executed on time-height cross sections, one per station per day When a combination of missing data and a rapidly changing wind field made the analysis questionable, the interpolation in time was abandoned and no observations were recorded for the given station over that time period. However, data were always available for at least two and usually three or all four stations.

The upper wind information contained on the cross sections was used to construct trajectories by three different methods. Trajectory duration was confined to $2 \mathrm{hr}$ because of the limited spatial coverage of the data.

In the first method, hourly readings of the wind vector at $230 \mathrm{~m}$ were transferred from the cross sections to maps of the urban area. The plotted maps were analyzed with conventional streamflow lines and isotachs. Because there was a maximum of only four simultaneous upper wind observations, the objectivity of the 230-m streamflow analysis was increased by first considering the distribution of isogons.

In an attempt to account for the wide fluctuation of tetroon altitudes, the second method used the average wind vector in the $100-400 \mathrm{~m}$ layer. Hourly readings of this average were plotted on the maps of the urban area and the analysis was performed as before.
Trajectories were constructed from the streamflowisotach analyses of the upper wind fields according to the same procedure already described for the construction of surface wind trajectories.

The utilization of the analyses as described above assumed that a realistic horizontal variation of the wind can be deduced from the available pibal and radiosonde winds. Because balloon-derived wind observations are often distorted by turbulence, the possibility that differences between the simultaneous observations at the four stations did not reflect real horizontal variations was considered.

The third method, therefore, averaged the direction and the speed of the simultaneous $100-400 \mathrm{~m}$ winds already used in the second method in order to arrive at one "grand average" wind for each hour which was assumed representative over the entire urban area. The wind trajectory was begun at the launch site and carried along with the appropriate fraction of each hourly "grand average" wind for the 2-hr duration.

Fig. 4 shows an example comparison of the two trajectories drawn from the surface wind fields and the "grand average" winds, respectively, with the tetroon trajectory of Flight 54 .

\section{Discussion of predictions}

a. Predictions from corrected surface wind trajectories for control group. Prediction errors were determined by

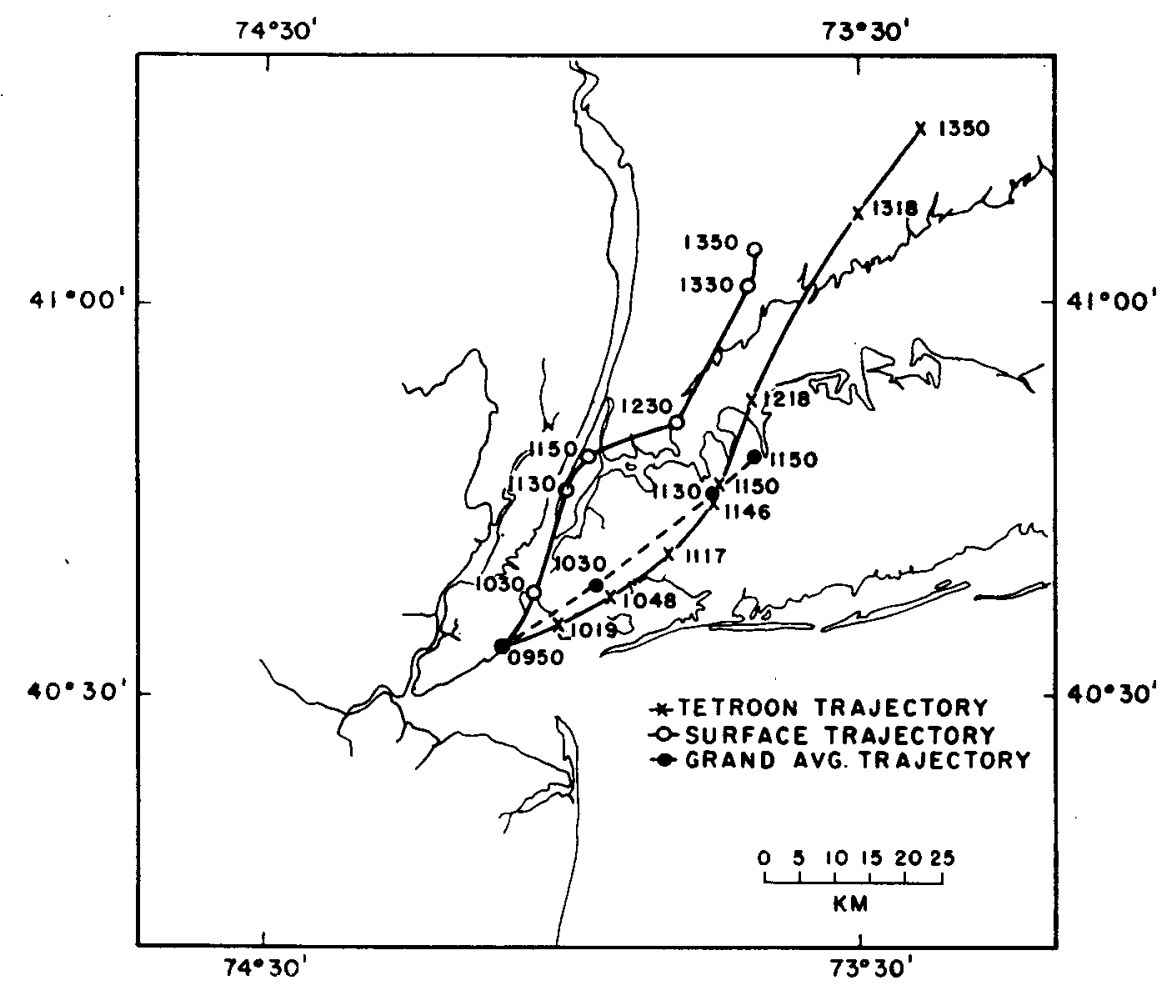

FIG. 4. Surface-wind-derived trajectory, "grand average" upper wind trajectory and tetroon trajectory of Flight 54 launched 0947 EST 21 June 1965 from Great Kills Park, Richmond. The times of several radar observations of tetroon position are indicated. 


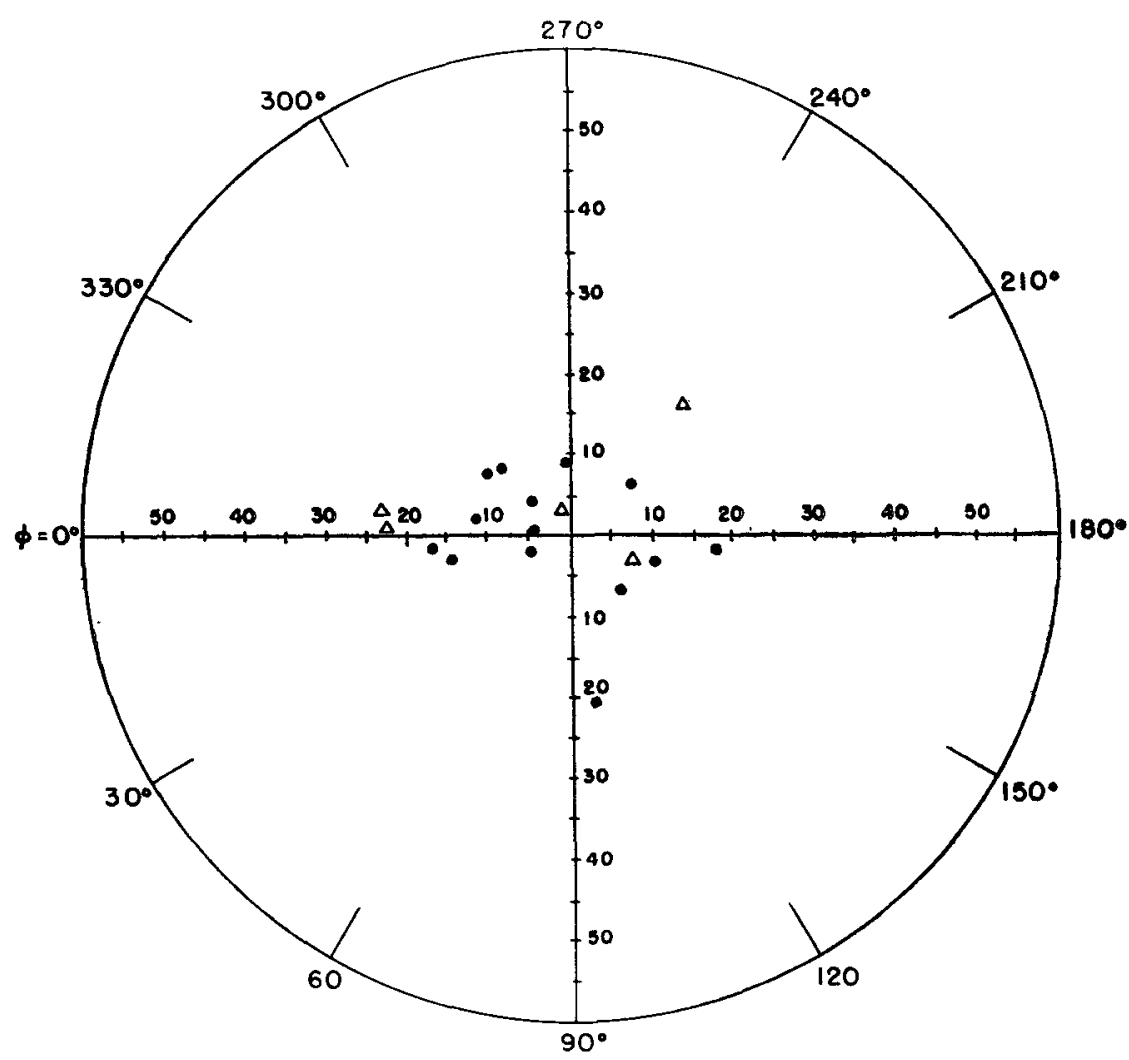

F1G. 5. Distribution of prediction errors for control group $\mathbf{P}+$ MVE predictions of 2-hr (solid circles) and 4-hr (triangles) tetroon positions. Distance measured in $\mathrm{km}$.

measuring the vector displacement between the position determined by addition of the mean vector error and the actual tetroon position. Mean prediction errors were computed for the 2- and 4-hr distributions by obtaining the means of the orthogonal components, the same procedure employed for the computation of the mean vector errors. The results for the 2 - and 4 -hr duration, surface wind vs tetroon trajectories of the control group, given in Table 1 , include the mean vector errors (no correction); the mean prediction errors (after applying the mean vector error correction); the rms of the vector error magnitudes; the rms of the prediction error magnitudes; and the percentage reduction of the rms errors.

Fig. 5 shows the distribution of prediction errors for

TABLE 1. Control group 2- and 4-hr duration mean vector errors, mean prediction errors, rms vector and prediction errors and percentage of error reduction. Error magnitudes are in $\mathrm{km}$.

\begin{tabular}{cccccc}
\hline MVE & MPE & $\begin{array}{c}\text { rms } \\
\text { vector } \\
\text { errors }\end{array}$ & $\begin{array}{c}\text { rms } \\
\text { predic- } \\
\text { tion } \\
\text { errors }\end{array}$ & $\begin{array}{c}\text { Percent- } \\
\text { age of } \\
\text { error } \\
\text { reduc- } \\
\text { tion }\end{array}$ \\
\hline $2 \mathrm{hr}$ & $12,157^{\circ}$ & $3,357^{\circ}$ & 16 & 12 & 27 \\
$4 \mathrm{hr}$ & $16,162^{\circ}$ & $7,311^{\circ}$ & 23 & 18 & 23
\end{tabular}

the 2- and 4-hr duration control group flights. From Table 1 and Fig. 5 it can be seen that the mean vector error predictors were effective in both randomizing the direction of the errors and in reducing the rms errors of the independent group of surface wind trajectories.

b. Predictions from upper wind trajectories. The trajectories drawn from the "grand average" winds were the most effective of the upper winds used to estimate the tetroon trajectories. Fig. 6 shows the distribution of vector errors for the 25 tetroon vs "grand average" upper wind trajectory comparisons. Note that the upper winds generally overestimated tetroon speed $\left(\varphi<90^{\circ}, \varphi>270^{\circ}\right)$.

Thus, the upper wind data were best utilized by averaging them in the vertical and the horizontal to obtain a single wind vector for the urban area for each time step. The 2-hr trajectories drawn from the "grand average" winds were superior to those drawn from the surface winds. They yielded a median of error magnitudes of $10 \mathrm{~km}$ as opposed to a median of $13 \mathrm{~km}$ for the latter group (despite the greatly reduced number of available upper wind observations and the questions of representativeness inherent in balloon-derived winds). However, as the following section suggests, the corrected surface wind trajectories yield prediction results 


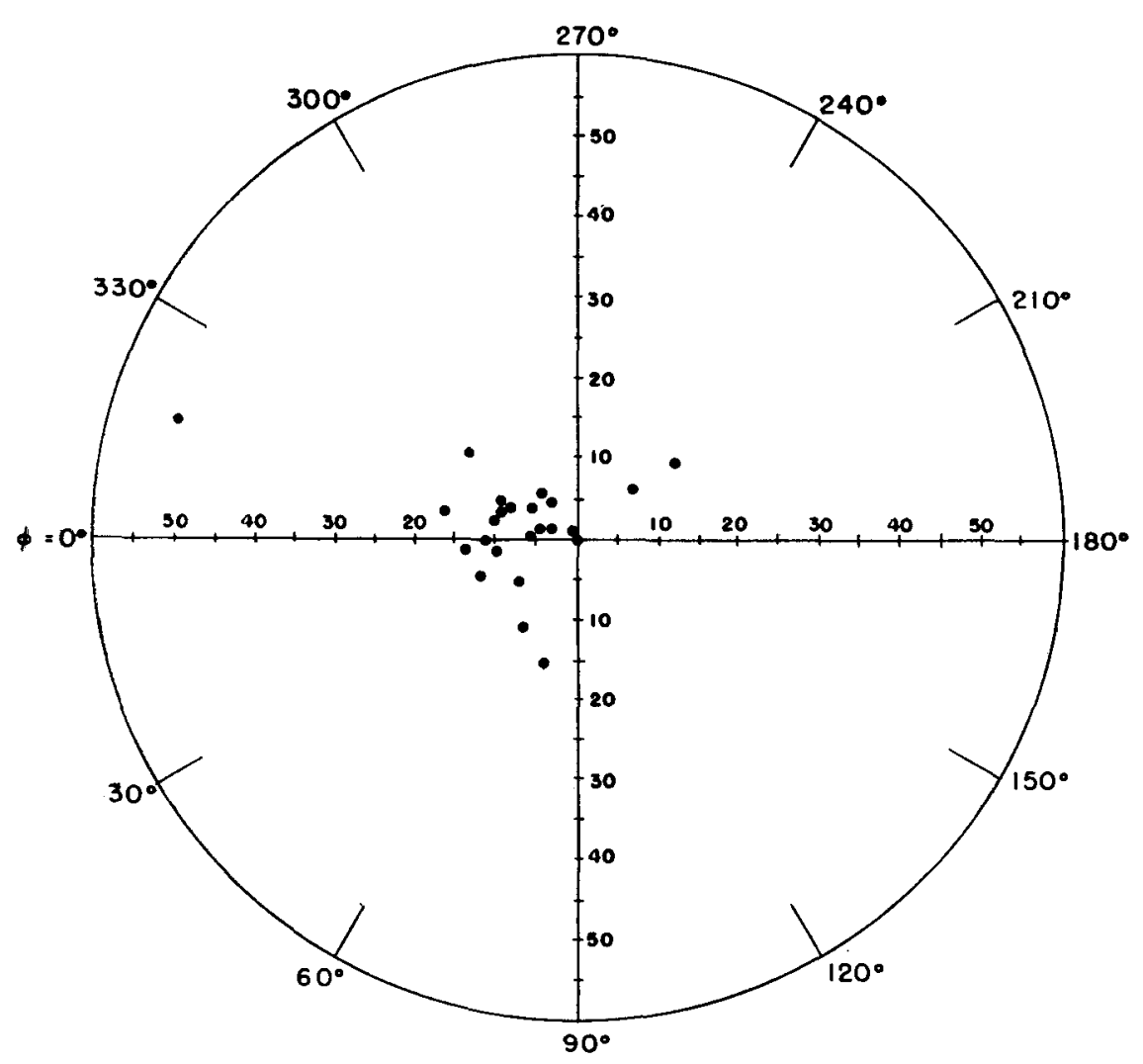

FIG. 6. Distribution of vector errors for 2 -hr comparisons of "grand average" jupper wind vs tetroon trajectories. Distance measured in $\mathrm{km}$.

more comparable to those obtained using the "grand average" trajectories. These results can be compared to those of Peterson (1966) who found adjusted surface winds more useful than the second standard level rawinsonde winds (at about $600 \mathrm{~m}$ ) for reconstructing boundary-layer tetroon trajectories on a synoptic scale.

c. Comparison of predictions. Table 2 lists the rms errors obtained from the comparison of the tetroon trajectories with 31 uncorrected surface wind trajectories of $2 \mathrm{hr}$ duration; 12 uncorrected surface wind trajectories of $4 \mathrm{hr}$ duration; 31 surface wind trajectories, corrected with the MVE, of $2 \mathrm{hr}$ duration; 12 surface wind trajectories, corrected with the MVE, of

TABLE 2. Root-mean-square errors in $\mathrm{km}$ for 2- and 4-hr duration trajectory comparisons of corrected and uncorrected surface wind and "grand average" upper wind trajectories.

\begin{tabular}{ccccc}
\hline \hline & & & & \\
Sfc wind & Sfc wind \\
$2 \mathrm{hr}$ & $4 \mathrm{hr}$ & $\begin{array}{c}\text { Sfc wind } \\
\text { and MVE } \\
2 \mathrm{hr}\end{array}$ & $\begin{array}{c}\text { Sfc wind } \\
\text { and MVE } \\
4 \mathrm{hr}\end{array}$ & $\begin{array}{c}\text { upper } \\
\text { wind } \\
2 \mathrm{hr}\end{array}$ \\
\hline 20 & 26 & 15 & 18 & 16 \\
\hline
\end{tabular}

$4 \mathrm{hr}$ duration; and 25 "grand average" wind trajectories of $2 \mathrm{hr}$ duration.

Table 3 lists the errors expressed as a percentage of the tetroon range for each flight in the same five categories as in Table 2. Table 3 shows that the MVE corrections increased the error in roughly $30 \%$ of the adjustments of surface wind trajectories. The existence of the typical Ekman wind profile, implied by the mean vector errors (and the majority of vector errors), is therefore a poor assumption under certain circumstances. That the median percentage errors were decreased after the MVE corrections, while the means were not, reflects the several very large error increases.

\section{Six-hour duration trajectories}

Of the original 55 tetroon flights, tetroon vs surface wind comparisons were extended to $6 \mathrm{hr}$ duration for only five. Although the number proved too small to compute meaningful predictors for verification with independent data, the percentage errors were determined. Interestingly, the mean percentage error for these five flights decreases with increasing duration. Thus, after $2 \mathrm{hr}$ duration the mean percentage error of 
the five comparisons was $54 \%$, after $4 \mathrm{hr}$ duration it was $35 \%$ and, after $6 \mathrm{hr}, 31 \%$. The 6 -hr positions on three of the surface wind trajectories were farther downstream than the tetroon, whereas the reverse was true for all five cases after $2 \mathrm{hr}$ duration.

\section{Mean altitude trajectories}

In order to determine whether the low-level trajectories could be more accurately reproduced by using upper winds at more representative altitudes, "mean altitude trajectories" were constructed for the five best documented flights, the altitude information being made available by helicopter tracking. Preparation of these trajectories was identical to that of the $230-\mathrm{m}$ trajectories except that the winds were taken at the observed mean altitude for each flight. These means varied between 170 and $395 \mathrm{~m}$.

The sample is too small to generalize about the prediction skill to be expected from using this method. The average percentage error of the five comparisons, however, is only $2 \%$ smaller than that computed for the same flights using the "grand average" winds.

\section{Conclusions}

Comparison of the rms errors of the corrected 2-hr surface wind trajectories and the "grand average" wind trajectories indicates that a slightly better estimate of tetroon position is obtained using the former data. However, since the difference is small, the decision whether to utilize low spatial density observations of planetary boundary layer winds or high spatial density surface wind observations can be made on the basis of manpower and instrumentation availability.

The magnitudes of the errors in predicting tetroon positions varied considerably, even when expressed as a percentage of the downwind tetroon range.

Although the correction of surface wind trajectories to account for vertical wind shear reduced the rms errors and the median percentage errors, mean percentage errors were not reduced. The magnitudes of the errors, even with the MVE corrections, were disappointingly high. They could not be reduced further because of the combined effect of the wide variation of tetroon altitudes and the complex thermal structure of the New York City atmosphere recently documented by Bornstein (1968). Undoubtedly, the wind structure of the regime was in a large measure determined by the presence, intensity and depths of the elevated and surface based temperature inversions discussed in the above study; knowledge of the surface wind field was often not sufficient to deduce the three-dimensional variations.

The errors obtained from the comparisons of the tetroon trajectories with the upper wind data can be
Table 3. Percentage errors for each flight for 2- and 4-hr trajectory comparisons of corrected and uncorrected surface wind and "grand average" upper wind trajectories.

\begin{tabular}{|c|c|c|c|c|c|}
\hline $\begin{array}{c}\text { Flight } \\
\text { number }\end{array}$ & $\begin{array}{l}\text { Sfc wind } \\
2 \mathrm{hr}\end{array}$ & $\begin{array}{c}\text { Sfc wind } \\
4 \mathrm{hr}\end{array}$ & $\begin{array}{l}\text { Sfc wind } \\
\text { and } \\
\text { MVE } \\
2 \mathrm{hr}\end{array}$ & $\begin{array}{l}\text { Sfc wind } \\
\text { and } \\
\text { MVE } \\
4 \mathrm{hr}\end{array}$ & $\begin{array}{c}\text { "Grand } \\
\text { average" } \\
\text { upper wind } \\
2 \mathrm{hr}\end{array}$ \\
\hline 2 & 24 & & 12 & & 25 \\
\hline 3 & 61 & & 43 & & 35 \\
\hline 5 & 45 & & 38 & & 02 \\
\hline 7 & 49 & 48 & 20 & 27 & 23 \\
\hline 11 & 56 & & 23 & & 120 \\
\hline 13 & 23 & & 49 & & 50 \\
\hline 15 & 19 & & 42 & & 10 \\
\hline 16 & 60 & & 24 & & 20 \\
\hline 18 & 14 & & 78 & & \\
\hline 19 & 90 & & 51 & & 33 \\
\hline 20 & 20 & & 127 & & 243 \\
\hline 21 & 82 & 76 & 35 & 43 & 64 \\
\hline 22 & 14 & & 92 & & 80 \\
\hline 25 & 07 & & 15 & & \\
\hline 32 & 35 & & 97 & & 75 \\
\hline 35 & 42 & 13 & 113 & 78 & \\
\hline 36 & 36 & & 90 & & 67 \\
\hline 39 & 69 & 49 & 27 & 13 & 22 \\
\hline 40 & 39 & 24 & 39 & 34 & 46 \\
\hline 41 & 46 & 09 & 14 & 46 & 20 \\
\hline 42 & 32 & 19 & 36 & 68 & 32 \\
\hline 45 & 63 & 47 & 29 & 22 & 09 \\
\hline 46 & 28 & 14 & 15 & 26 & 31 \\
\hline 47 & 28 & 29 & 15 & 05 & 29 \\
\hline 49 & 23 & & 16 & & \\
\hline 50 & 30 & & 20 & & \\
\hline 51 & 67 & & 51 & & 10 \\
\hline 52 & 52 & & 22 & & \\
\hline 53 & 73 & 34 & 62 & 25 & 33 \\
\hline 54 & 51 & 31 & 43 & 08 & 17 \\
\hline 55 & 49 & & 27 & & 22 \\
\hline Median & 42 & 30 & 36 & 26 & 31 \\
\hline Mean & 43 & 33 & 44 & 33 & 45 \\
\hline
\end{tabular}

attributed not only to the variation of tetroon altitudes but also to the non-representativeness of the pibal and low-level radiosonde wind observations. A reasonably small error in wind velocity unfortunately creates a sizeable error in estimating the position of a particle at the end of a trajectory of the order of $40 \mathrm{~km}$.

Acknozeledgments. The author wishes to thank Dr. Ben Davidson for the initial inspiration for the study and to acknowledge his guidance throughout the investigation. The helpful suggestions of Dr. Jerome Spar during the preparation of the manuscript are also gratefully acknowledged. The field work was done in conjunction with the Air Resources Laboratory, ESSA.

\section{REFERENCES}

Air Resources Laboratory, 1966: A catalogue of radar-positioned constant-volume balloon (tetroon) flights. Tech. Paper No. 58, Environmental Science Services Administration, U. S. Weather Bureau, 293 pp.

Angell, J. K., 1961 : Use of constant level balloons in meteorology 
Advances in Geopllysics, Vol. 8, New York, Academic Press, Inc., p. 158.

—, D. H. Pack, G. C. Holzeworth and C. R. Dickson, 1966: Tetroon trajectories in an urban atmosphere. $J . A p p l$. Meteor., 5, 565-572.

Bornstein, R., 1968: Vertical temperature distributions over the New York City area. J. Appl. Meteor., 7, 575-582.

Davidson, B., 1967: A summary of the New York urban air pollution dynamics research program. $J$. Air Pollution Control A ssoc., 17, 154-158.

Hass, W. A., W. H. Hoecker, D. H. Pack and J. K. Angell, 1967: Analysis of low-level, constant volume balloon (tetroon) flights over New York City. Quart. J. Roy. Meteor. Soc., 93, 483-493.

Peterson, K. R., 1966: Estimating low-level tetroon trajectories. J. Appl. Meteor., 5, 553-564. 